\title{
Effects of glucose sensing/signaling on oxidative stress response in glucose repression mutants of Schizosaccharomyces pombe
}

\author{
B. Palabiyik, F. Jafari Ghods and E. Onay Ucar \\ Department of Molecular Biology and Genetics, Faculty of Science, \\ Istanbul University, Istanbul, Turkey \\ Corresponding author: B. Palabiyik \\ E-mail: bediag@istanbul.edu.tr
}

Genet. Mol. Res. 12 (4): 5046-5056 (2013)

Received June 13, 2013

Accepted October 2, 2013

Published October 25, 2013

DOI http://dx.doi.org/10.4238/2013.October.25.3

\begin{abstract}
The resistant to glucose repression mutants of Schizosaccharomyces pombe (ird5, ird13, and ird14) have a high tolerance to oxidative stress induced by $\mathrm{H}_{2} \mathrm{O}_{2}$. In all ird mutants, the increased expression level of the $f b p l$ gene can be interpreted as a lack of glucose repression in these mutants. To investigate the mechanisms of the oxidative stress response in ird mutants, we analyzed the transcription of stress response-related genes, sod1, ctt1, atfl, papl, and styl, under stressed and non-stressed conditions. We then analyzed the phosphorylation state of the Sty1-MAP kinase in ird mutants. Our findings support the concept of an adaptive response to oxidative stress in these mutants. In addition, these results imply that either glucose signaling mechanisms leading to glucose repression and glucose utilization as an energy source are regulated apart from each other or, like Saccharomyces cerevisiae, S. pombe might have additional glucose detection systems.
\end{abstract}

Key words: Schizosaccharomyces pombe; Glucose detection; Oxidative stress response; Glucose repression; $f b p 1 ; h x k 2$ 


\section{INTRODUCTION}

Glucose plays important regulatory roles in the expression of many genes related to glucose sensing/signaling, glucose transport, glucose catabolism, utilization of alternative carbon sources, and stress response pathways (Carlson, 1999; Johnston, 1999; Rolland et al., 2002; Chen et al., 2003, 2008). Unlike Saccharomyces cerevisiae, regulatory mechanisms in glucose sensing and signaling are not fully understood in fission yeast (Schizosaccharomyces pombe). Nevertheless, it has been reported that glucose is detected by the Git3 G protein-coupled receptor, which generates an intracellular signal via the cyclic AMP (cAMP)-dependent protein kinase A (PKA) pathway in S. pombe (Welton and Hoffman, 2000; Hoffman, 2005). Multiple genes (ghtl-ght6) encoding hexose transporters have also been identified in S. pombe (Heiland et al., 2000). Recently, an Ssp2 Snf1-like protein kinase, which regulates glucose repression/de-repression, has been identified in S. pombe by Matsuzawa et al. (2012).

Glucose sensing also triggers the activation of adenylate cyclase to elevate cAMP, which results in PKA repression of the transcription of the $f b p 1$ gene that encodes fructose-1,6-biphosphatase in S. pombe (Hoffman and Winston, 1991; Byrne and Hoffman, 1993). PKA inhibits conjugation, sporulation, respiration, thermotolerance, and utilization of alternative carbon sources (DeVoti et al., 1991; Maeda et al., 1990, 1994; Fernandez et al., 1997; Riberio et al., 1997).

Glucose starvation potentiates a stress-activated mitogen-activated protein kinase (MAPK) pathway. MAPK cascades are well-known, highly conserved signal transduction pathways possessing three protein kinases, the MAPK, the MAPK kinase (MAPKK), and the MAPKK kinase (MAPKKK) (Degols et al., 1996; Stettler et al., 1996; Samejima et al., 1997; Shiozaki et al., 1997). One of the components is the spc1/sty1 MAPK, which plays an important role in the regulation of downstream targets by triggering two transcriptional activators, Atf1-Pcr1 and Pap1 (Ikner and Shiozaki, 2005). Sty1 is required for many processes that are also negatively regulated by PKA, including mating and sporulation, gluconate transport, and thermotolerance (Shiozaki and Russell, 1996; Wilkinson et al., 1996). Neely and Hoffman (2000) showed that this pathway regulated the transcription of the $f b p 1$ gene by protein-DNA interactions at upstream activation site 1 (UAS1) and UAS2 of this gene.

On the other hand, the high resistance to oxidative stress under glucose depletion either involves the induction of a wide array of stress-responsive genes due to carbon stress (Madrid et al., 2004) or is a defense mechanism against the increased accumulation of reactive oxygen species that are derived from aerobic respiration (Roux et al., 2009).

Lin et al. (2002) reported that an S. cerevisiae strain with a deletion of the HXK2 gene, which is involved in glycolysis, mimics the effect of growth in low glucose and extends the life span. Recently, lowering caloric intake by limiting glucose was found to extend life span in fission yeast (Chen and Runge, 2009; Roux et al., 2010; Zuin et al., 2010).

In this study, we investigated the effects of glucose sensing/signaling on stress-activated MAPK pathways using glucose repression-resistant mutant strains (ird5, ird13, and ird14) of S. pombe.

\section{MATERIAL AND METHODS}

\section{Chemicals and reagents}

Anti-phospho-p38 MAPK (Tyr182) polyclonal antibody and goat anti-rabbit IgG 
(horseradish peroxidase-conjugated) antibody were purchased from Thermo Scientific, USA. ECL-Plus Western Blotting Detection system was purchased from Amersham, USA. Other reagents were obtained from Sigma Aldrich, USA.

\section{Yeast strains and growth media}

S. pombe Lindner liquefaciens (wild type, $972 h^{-}$) and glucose repression resistant constitutive invertase mutants (ird5, ird13, and ird14) (Kig et al., 2005) were used in this study. The growth medium, containing $0.5 \%$ yeast extract, $3 \%$ sucrose, and $400 \mu \mathrm{g} / \mathrm{mL} 2$-deoxy-Dglucose (Rincon et al., 2001) was used for the selection of ird mutants. The cells were grown in the standard rich yeast extract liquid or agar medium (YEL or YEA, respectively). The YEL medium contained $3 \%$ glucose (repressed condition) or $0.5 \%$ glucose (glucose starvation condition), and the YEA medium contained $0.1 \%$ glucose plus $3 \%$ glycerol (de-repressed condition).

\section{Induction of oxidative stress}

Exponentially growing $S$. pombe cells (wild type, $\operatorname{ird} 5$, $\operatorname{ird} 13$, and $\operatorname{ird14}$ ) were split into two tubes. In the experimental group, $2 \mathrm{mM}$ hydrogen peroxide $\left(\mathrm{H}_{2} \mathrm{O}_{2}\right)($ Sigma, H1009) was added to the medium. The control group was not exposed to oxidative stress. After 1 $\mathrm{h}$, both experimental and control cells were removed by centrifugation, washed with sterile distilled water, and plated on YEA. After incubation at $30^{\circ} \mathrm{C}$ for $3-4$ days, the survival rates were calculated as a percentage of the numbers of colonies obtained from the serial dilutions of control and experimental cells.

\section{Hydrogen peroxide consumption by cells}

At the end of oxidative stress implementation, the remaining $\mathrm{H}_{2} \mathrm{O}_{2}$ concentration in the medium was detected by the phenol-red method (Pick and Keisari, 1980) to check the $\mathrm{H}_{2} \mathrm{O}_{2}$ consumption of the cells. One milliliter of phenol-red buffer, which contained $40 \mathrm{mM} \mathrm{NaCl}$, $10 \mathrm{mM}$ potassium phosphate buffer, $\mathrm{pH} 7.0,0.1 \mathrm{~g} / \mathrm{mL}$ phenol-red, and $8.5 \mathrm{U} / \mathrm{mL}$ horseradish peroxidase, was added to a $500-\mu \mathrm{L}$ cell suspension, and the reaction mixture was incubated at $37^{\circ} \mathrm{C}$ for $5 \mathrm{~min}$. The absorbance of the resulting purple complex was measured at $550 \mathrm{~nm}$. The concentration of $\mathrm{H}_{2} \mathrm{O}_{2}$ in the medium was calculated according to a standard graph prepared by using absorbance values of the mixtures containing $1,10,100$, and $200 \mu \mathrm{M} \mathrm{H}_{2} \mathrm{O}_{2}$.

\section{Cell disruption and extraction of soluble proteins}

The yeast cells were homogenized with lysis buffer containing $50 \mathrm{mM}$ Tris- $\mathrm{HCl}$, $\mathrm{pH}$ 6.8, 5 $\mathrm{mM}$ ethylenediaminetetraacetic acid, $150 \mathrm{mM} \mathrm{NaCl}, 100 \mathrm{mM}$ dithiothreitol, $10 \%$ glycerol, and protease inhibitor cocktail. The extract was centrifuged at $12,000 \mathrm{~g}$ for $20 \mathrm{~min}$ at $4^{\circ} \mathrm{C}$ to remove insoluble material. The protein concentration of the supernatant was determined by the Bradford assay.

\section{Polyacrylamide gel electrophoresis (PAGE) and Western blot analysis}

For sodium dodecyl sulfate (SDS)-PAGE and Western blotting, protein extracts were 
denatured in sample buffer and boiled for $3 \mathrm{~min}$. Equal amounts of protein $(50 \mu \mathrm{g} / \mathrm{well})$ were analyzed by $10 \%$ SDS-PAGE. After electrophoresis, proteins were transferred to polyvinylidene fluoride membranes using a BIO-RAD Semi-Dry apparatus. Membranes were blocked with 5\% bovine serum albumin fraction V (in Tris-buffered saline with Tween 20) at room temperature for $1 \mathrm{~h}$. Primary antibody against the phospho-p38 MAPK was used at 1:500 for $1 \mathrm{~h}$ at room temperature. Peroxidase-conjugated goat anti-rabbit secondary antibody was used at 1:100 for $1 \mathrm{~h}$ at room temperature. Protein bands were detected with ECL-plus and quantitative analysis was performed with ChemiDoc MP and the ImageLab 4.0.1 Software (BIO-RAD).

\section{RNA isolation and cDNA synthesis}

Total RNA was isolated using a High Pure RNA Isolation Kit (Roche) following manufacturer instructions. First-strand oligo (dT)-primed cDNA synthesis was performed using the Transcriptor High Fidelity cDNA Synthesis Kit (Roche) according to the manufacturer protocol.

\section{Real-time polymerase chain reaction (PCR)}

Quantitative real-time PCR (RT-PCR) was performed with the FastStart SYBR Green Master Kit (Roche), using the synthetic first-strand cDNA as a template, following manufacturer instructions. Briefly, the reaction mixture consisted of $25 \mu \mathrm{L}$ FastStart SYBR Green Master, $0.2 \mu \mathrm{M}$ forward and reverse primers, and $0.1 \mu \mathrm{g}$ cDNA made up to $50 \mu \mathrm{L}$ with ultrapure nuclease-free water. The PCR conditions were set as follows: $95^{\circ} \mathrm{C}$ for $10 \mathrm{~min}$ (preincubation), followed by 40 cycles of $95^{\circ} \mathrm{C}$ for $10 \mathrm{~s}, 53^{\circ} \mathrm{C}$ for $10 \mathrm{~s}$, and $72^{\circ} \mathrm{C}$ for $20 \mathrm{~s}$. The final step included a gradual temperature increase from $55^{\circ}$ to $95^{\circ} \mathrm{C}$ at the rate of $1{ }^{\circ} \mathrm{C} / 10 \mathrm{~s}$ to enable melting curve data collection. A non-template control was run, and serial dilutions (1, $1: 10$, and 1:100) of the reference (actin gene, act 1) and the target genes were included in every assay. The amplification specificity of each reaction was verified by melting curve analysis. Expression levels were normalized against the reference gene, actl. The relative gene expression levels were determined according to the method of Pfaffl (2001).

\section{Statistical analysis}

Data are reported as means \pm standard deviation for three experiments. Statistical comparisons were made using one-way analysis of variance (ANOVA) for RT-PCR and Western blot analysis of GraphPad Prism 5. Differences in mean values were considered to be significant when $\mathrm{P}<0.05$.

\section{RESULTS AND DISCUSSION}

\section{Resistance of $\mathrm{ird}$ mutants against oxidative stress}

The survival rates of $i r d$ mutants and wild-type cells growing in different glucose concentrations (repressed, starvation, and de-repressed conditions) were compared under a mild oxidative stress. The ird mutants were found to be more resistant to oxidative stress than the 
wild-type strain in each condition. All ird mutants and the wild-type strain exhibited resistance to oxidative stress when they were grown in glucose starvation or de-repressed conditions (Figure 1). These results supported our previous results related to ird11 studies (Suslu et al., 2011; Palabiyik et al., 2012). These findings imply an adaptive response to oxidative stress in these mutants and links between glucose sensing/signaling and the oxidative stress response.

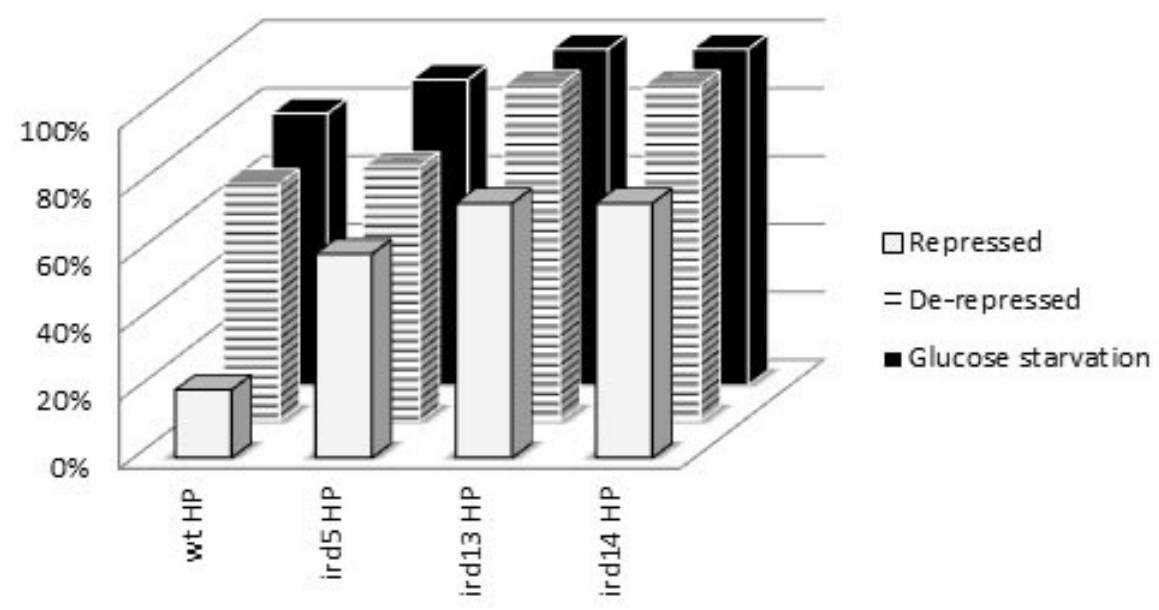

Figure 1. Survival rates of the wild-type and $i r d$ mutants under mild-oxidative stress condition. Exponentially grown mutant and wild-type cells in different glucose-containing media $(0.1 \%$ glucose and $3 \%$ glycerol, $0.5 \%$ glucose and 3\% glucose providing de-repressed, starvation and repressed conditions, respectively) were exposed to $\mathrm{H}_{2} \mathrm{O}_{2}$ for $1 \mathrm{~h}$ and were compared with untreated cells. $\mathrm{wt}=$ wild type; $\mathrm{HP}=$ treated with $\mathrm{H}_{2} \mathrm{O}_{2}$.

In addition, in this study, we checked that the $\mathrm{H}_{2} \mathrm{O}_{2}$ in the medium was entirely consumed by either the wild-type strain or ird mutants after $1 \mathrm{~h}$ of $\mathrm{H}_{2} \mathrm{O}_{2}$ treatment (data not shown). This finding indicated that the oxidative stress resistance of ird mutants did not arise from inadequate $\mathrm{H}_{2} \mathrm{O}_{2}$ uptake.

\section{Ability to escape glucose repression in ird mutants}

The expression profile of the $f b p 1$ gene in ird mutants was compared with that in the wild-type strain. The $f b p l$ gene is used as a marker for glucose repression because it is transcriptionally repressed by glucose (Hoffmann and Winston, 1989, 1990), and it is induced by glucose starvation (Kanoh et al., 1996; Neely and Hoffman, 2000).

Under repressed conditions, $f b p 1$ expression in $i r d 5$, ird13, and ird14 mutants was increased 4- to 8-fold compared to the wild-type strain (Figure 2). This finding is consistent with that of another study, which found reduced glucose consumption by ird mutants (Kig et al., 2005). Therefore, the elevated expression of the $f b p l$ gene in ird mutants (Figure 2) might be because of a lack of glucose repression. In addition, the high resistance of ird mutants to oxidative stress might result from a lack of glucose repression because it is known that glucose depletion causes resistance to oxidative stress in S. pombe (Madrid et al., 2004; Roux et al., 2009). 

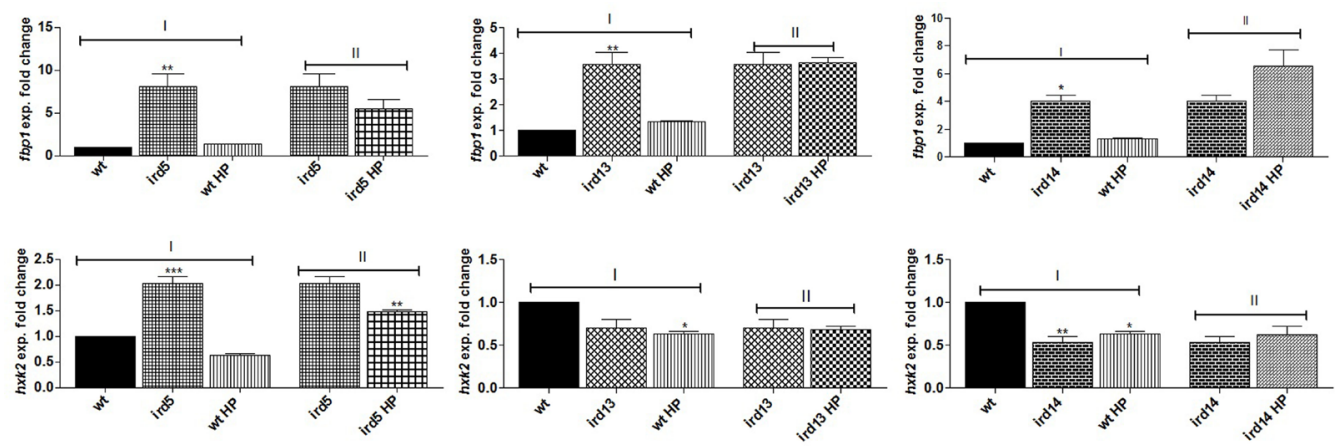

Figure 2. Expression levels of $f b p 1$ and $h x k 2$ genes. The expression levels of $f b p 1$ and $h x k 2$ genes in wild-type and ird mutant cells treated with $\mathrm{H}_{2} \mathrm{O}_{2}$ or untreated, after grown in rich media containing $3 \%$ glucose (repressed media), were determined according to Pfaffl method relative to the actin gene. Significant differences between $\mathbf{I}$. untreated wild-type and untreated ird mutants and treated wild-type cells and II. untreated and treated ird mutants were evaluated by the Tukey test. ***P $<0.0001$; ** $<<0.001$; $* \mathrm{P}<0.05$. wt $=$ wild type; $\mathrm{HP}=$ treated with $\mathrm{H}_{2} \mathrm{O}_{2}$.

The hxk2 gene, which is required for glucose metabolism (Petit et al., 1996), was analyzed in ird mutants and compared with the wild-type strain. The expression level of the $h x k 2$ gene increased approximately 2-fold in the ird5 mutant (Figure 2) while it decreased in the ird 13 and ird 14 mutants compared to the wild-type strain. These results indicate that glucose can be metabolized faster in the ird5 mutant than in the ird 13 and ird14 mutants, as with the ird11 mutant (Palabiyik et al., 2012). We suggest that the oxidative stress resistance of $S$. pombe may be associated with the glucose sensing/signaling pathways rather than the availability and metabolism of glucose.

\section{Oxidative stress resistance of $i r d$ mutants}

To investigate the possible mechanism underlying the high oxidative stress resistance in $\operatorname{ird} 5$, ird13, and ird 14 mutants, the expression levels of the $c t t 1$ and sodl genes were examined. The expression levels of the sodl and $\mathrm{ctt} 1$ genes were not increased in ird mutants under non-stressed conditions (Figure 3). With the exception of the ird5 mutant, the expression level of the sodl gene increased in all mutant cell lines under stressed conditions. In addition, the expression level of the $\mathrm{ctt} 1$ gene was significantly increased in the ird14 mutant but not in the other mutants (Figure 3). These results suggest that the resistance of ird mutants to oxidative stress appears not to be related to the constitutive activation of either sodl or cttl.

Atf1 and Pap1 are known to be involved in the regulation of the cellular defense mechanism(s) against increasing oxidative stress in aerobically growing, glucose-depleted cells (Madrid et al., 2004). These transcription factors have been proposed to be activated under mild oxidative stress conditions in S. pombe (Quinn et al., 2002). In this study, a mild oxidative stress condition was induced to specifically activate the Atf1 and Pap1 transcription factors. As expected, the expression levels of atfl and pap1 were increased in wild-type cells under mild oxidative stress, as well as in all three mutant cell lines. With the exception of $i d r 5$, the expression level of atfl did not significantly increase in the mutants under non-stressed conditions. However, pap1 expression levels were significantly higher in the $\operatorname{ird} 5$, ird13, and ird14 mutants than in the wild-type strain under stressed conditions (Figure 4). These results 
suggest that the resistance of the ird5 and ird13 mutants to oxidative stress appears to be related to the constitutive activation of pap 1, but the resistance of the ird14 mutant to oxidative stress is not.
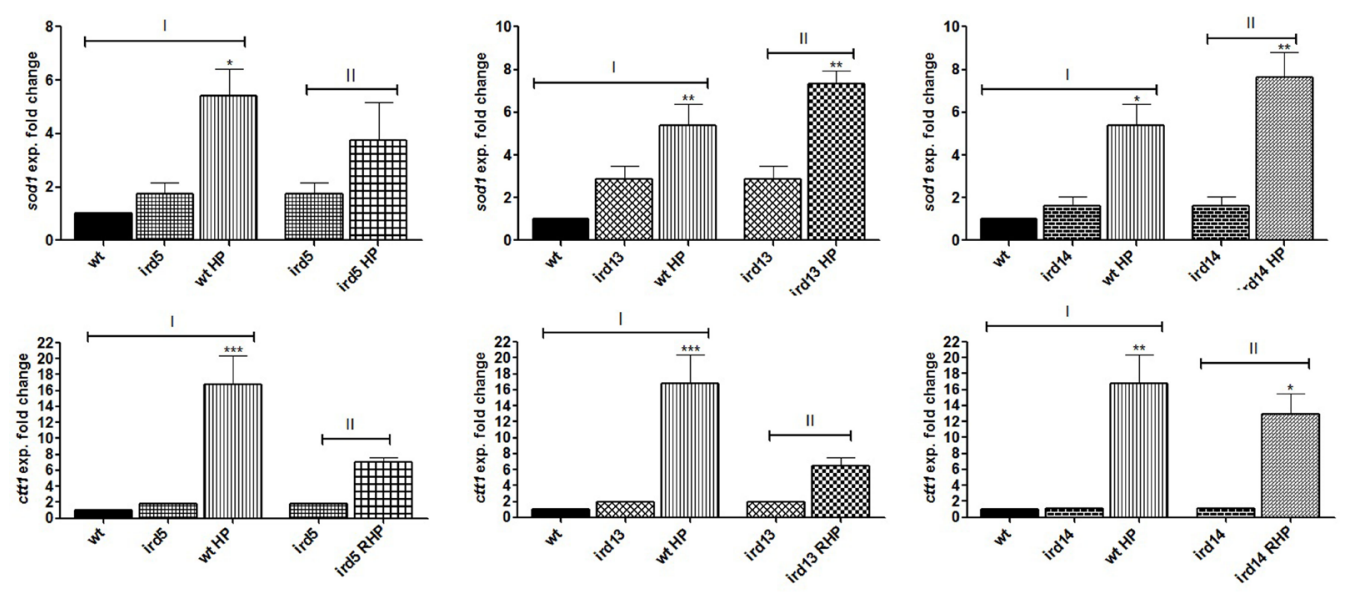

Figure 3. Expression levels of $c t t 1$ and $\operatorname{sod} 1$ genes. The expression levels of $c t t 1$ and $\operatorname{sod} 1$ genes in treated wildtype and ird mutants and untreated cells grown under repressed condition were determined according to Pfaffl method relative to the actin gene. Significant differences between $\mathbf{I}$. untreated wild-type and untreated ird mutants and treated wild-type cells and II. untreated and treated $i r d$ mutants were evaluated by the Tukey test. $* * * \mathrm{P}<$ $0.0001 ; * * \mathrm{P}<0.001 ; * \mathrm{P}<0.05$. wt = wild type; $\mathrm{HP}=$ treated with $\mathrm{H}_{2} \mathrm{O}_{2}$.
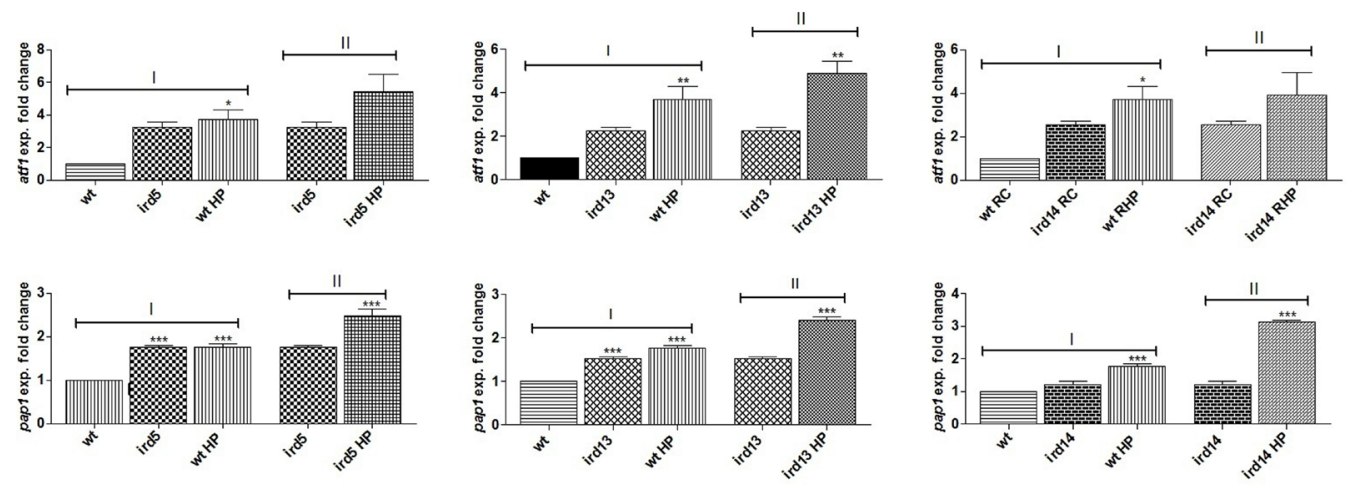

Figure 4. Expression levels of atfl and pap1 genes. The expression levels of atfl and pap1 genes in treated and untreated wild-type and ird mutant cells grown under repressed condition were determined according to Pfaffl method relative to the actin gene. Significant differences between I. untreated wild-type and untreated ird mutants and treated wild-type cells and II. untreated and treated ird mutants were evaluated by the Tukey test. ***P< $0.0001 ; * * \mathrm{P}<0.001 ; * \mathrm{P}<0.05$. wt $=$ wild type; $\mathrm{HP}=$ treated with $\mathrm{H}_{2} \mathrm{O}_{2}$.

We compared the expression level of the sty 1 gene encoding the Sty 1 protein kinase, which is an upstream regulator of the Atf1 and Pap1 transcription factors, in S. pombe ird mutants and wild-type cells (Ikner and Shiozaki, 2005). In this study, a significant increase was observed in styl expression in the ird5, ird13, and ird14 mutants under non-stressed condi- 
tions (Figure 5). The expression level of styl significantly increased in wild-type cells under stressed conditions. As shown in Figure 5, under the same conditions, the styl expression level increased in the mutants with the exception of the ird 13 mutant. The phosphorylation level of the Sty1 protein was analyzed by immunoblotting with anti-phospho $\mathrm{p} 38\left(\mathrm{Thr}^{182}\right)$ in wild-type and $\operatorname{ird} 5$, ird13, and ird14 mutant cells treated with $\mathrm{H}_{2} \mathrm{O}_{2}$ (Figure 6). With the exception of the $\operatorname{ird} 13$ mutant, increased phosphorylation of Sty1-MAPK was observed in the ird mutants under non-stressed conditions, while the phosphorylation state increased dramatically in all ird mutants under stressed conditions. These findings suggest that the resistance of ird mutants to oxidative stress might result from the constitutive activation of styl and/or increased phosphorylation of Sty1.
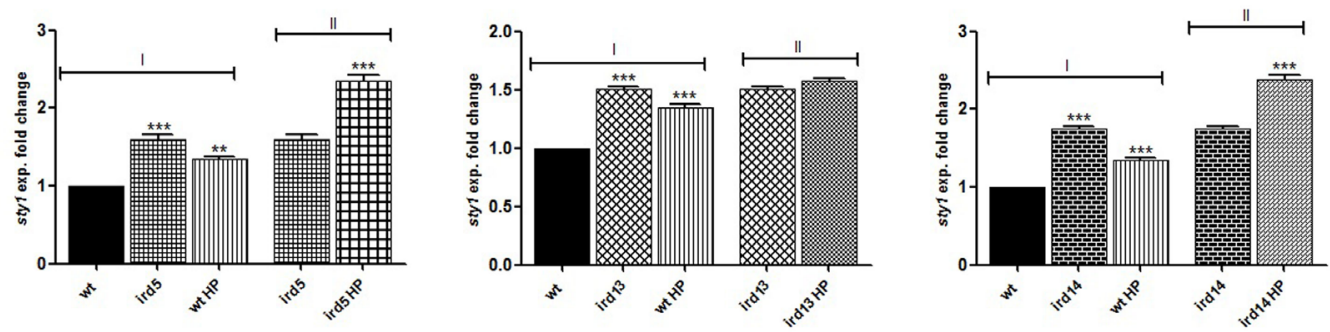

Figure 5. Expression levels of the sty 1 gene. The expression levels of the styl gene in wild-type and ird mutants treated with $\mathrm{H}_{2} \mathrm{O}_{2}$ or untreated, after grown in rich media containing $\% 3$ glucose (repressed media), were determined according to Pfaffl method relative to the actin gene. Significant differences between I. untreated wild-type and untreated ird mutants and treated wild-type cells and II. untreated and treated ird mutants were evaluated by the Tukey test. ${ }^{* * *} \mathrm{P}<0.0001 ; * * \mathrm{P}<0.001 ; * \mathrm{P}<0.05$. wt $=$ wild type; $\mathrm{HP}=$ treated with $\mathrm{H}_{2} \mathrm{O}_{2}$.

A

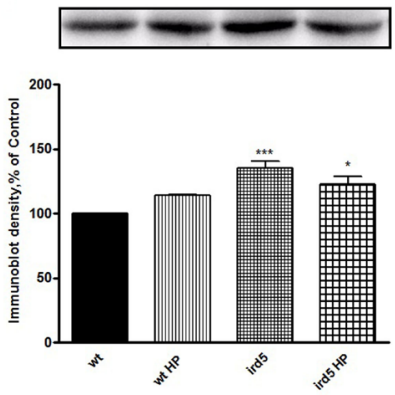

B

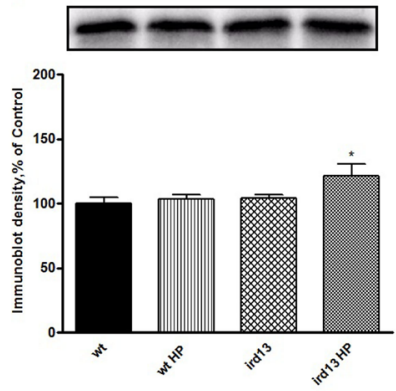

C

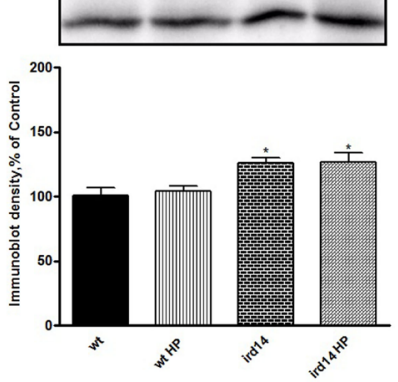

Figure 6. Detection of phosphorylated Sty1 by immunoblotting. The phosphorylated Sty1 protein was analyzed by immunoblotting with anti-phosphorylated p38 $\left(\mathrm{Thr}^{182}\right)$ as described in "Experimental procedures" in wildtype and ird mutants treated with $\mathrm{H}_{2} \mathrm{O}_{2}$ or untreated, after grown in rich media containing $3 \%$ glucose (repressed media). A. $\operatorname{ird5}$. B. $i r d 13$. C. $\operatorname{ird14}$. All results were evaluated by the Tukey $t$-test. $* * * \mathrm{P}<0.0001 ; * * \mathrm{P}<0.001$; $* \mathrm{P}<0.05$. wt $=$ wild type; $\mathrm{HP}=$ treated with $\mathrm{H}_{2} \mathrm{O}_{2}$.

\section{CONCLUSIONS}

As summarized in Table 1, the reduced glucose consumption efficiency of ird mutants might cause a lack of glucose repression in these mutants. The significantly increased 
expression of $f b p 1$ in all ird mutants including ird11 (Palabiyik et al., 2012) can therefore be interpreted as a lack of glucose repression in these mutants. Additionally, inefficient glucose uptake in ird mutants can cause an increased oxidative stress response in $S$. pombe. This may be explained by the fact that PKA activated by glucose starvation with the stress-activated MAPK pathway regulates the transcription of downstream genes via protein-DNA interactions at UAS1 and UAS2 of the $f b p 1$ gene (Neely and Hoffman, 2000).

Table 1. Summary of some studies concerning resistant to glucose repression mutants of Schizosaccharomyces pombe.

\begin{tabular}{lccccc}
\hline & Wild type & ird5 & ird13 & ird14 & References \\
\hline Glucose repression & $91 \%$ & $73 \%$ & $41 \%$ & $21 \%$ & Kig et al., 2005 \\
Glucose consumption rate & $87 \%$ & $19 \%$ & $37 \%$ & $12 \%$ & Kig et al., 2005 \\
Expression level of $f b p 1$ according to wild type & - & x8 up regulation & x4 up regulation & x4 up regulation & This study \\
Expression level of $h x k 2$ according to wild type & - & x2 up regulation & Down regulation & Down regulation & This study \\
Resistance to oxidative stress under repressed condition & $20 \%$ & $60 \%$ & $75 \%$ & $75 \%$ & This study \\
\hline
\end{tabular}

Finally, lowering the caloric intake by reduced glucose consumption efficiency of ird mutants might lead to resistance to oxidative stress in these mutants. However, there is a conflict in our results related to the expression of the $f b p 1$ and $h x k 2$ genes in the ird 5 mutant (like that of the ird11 mutant; Palabiyik et al., 2012). Glucose detection in S. pombe occurs through a Git3 glucose-sensing receptor, which is encoded by the git 3 gene. This glucose receptor activity resembles the glucose signaling that is triggered by the cAMP-dependent PKA pathway (Welton and Hoffmann, 2000; Hoffman, 2005) and glucose utilization as an energy source that is started by glucose phosphorylation by the Hxk2 kinase enzyme, which is encoded by the $h x k 2$ gene. Taken together, this study implies that the deficiency of glucose repression in ird mutants might lead to resistance to oxidative stress in these mutants. In addition, glucose signaling mechanisms leading to glucose repression and glucose utilization as an energy source might be regulated apart from each other. Alternatively, like $S$. cerevisiae, S. pombe might have additional glucose detection systems. Our ongoing studies on this subject are important for understanding glucose sensing/signaling and glucose uptake in S. pombe. In this context, these mutants may be used as model systems for investigating glucose metabolism, glucose uptake, glucose sensing/signaling, and the oxidative stress response.

\section{ACKNOWLEDGMENTS}

We thank Prof. Dr. Alastair Aitken (University of Edinburgh) and Prof. Dr. Sezai Türkel (Uludağ University) for helpful advice, and Prof. Dr. Güler Temizkan and Dr. Cenk Kığ (Catholic University of Leuven) for suggestions. Research supported by the Istanbul University Research Fund (Projects \#1477 and \#20423).

\section{REFERENCES}

Byrne SM and Hoffman CS (1993). Six git genes encode a glucose-induced adenylate cyclase activation pathway in the fission yeast Schizosaccharomyces pombe. J. Cell Sci. 105 (Pt 4): 1095-1100.

Carlson M (1999). Glucose repression in yeast. Curr. Opin. Microbiol. 2: 202-207.

Chen BR and Runge KW (2009). A new Schizosaccharomyces pombe chronological lifespan assay reveals that caloric restriction promotes efficient cell cycle exit and extends longevity. Exp. Gerontol. 44: 493-502. 
Chen D, Toone WM, Mata J, Lyne R, et al. (2003). Global transcriptional responses of fission yeast to environmental stress. Mol. Biol. Cell 14: 214-229.

Chen D, Wilkinson CR, Watt S, Penkett CJ, et al. (2008). Multiple pathways differentially regulate global oxidative stress responses in fission yeast. Mol. Biol. Cell 19: 308-317.

Degols G, Shiozaki K and Russell P (1996). Activation and regulation of the Spc1 stress-activated protein kinase in Schizosaccharomyces pombe. Mol. Cell. Biol. 16: 2870-2877.

DeVoti J, Seydoux G, Beach D and McLeod M (1991). Interaction between ran1+ protein kinase and cAMP dependent protein kinase as negative regulators of fission yeast meiosis. EMBO J. 10: 3759-3768.

Fernandez J, Soto T, Vicente-Soler J, Cansado J, et al. (1997). Heat-shock response in Schizosaccharomyces pombe cells lacking cyclic AMP-dependent phosphorylation. Curr. Genet. 31: 112-118.

Heiland S, Radovanovic N, Hofer M, Winderickx J, et al. (2000). Multiple hexose transporters of Schizosaccharomyces pombe. J. Bacteriol. 182: 2153-2162.

Hoffman CS (2005). Glucose sensing via the protein kinase A pathway in Schizosaccharomyces pombe. Biochem. Soc. Trans. 33: 257-260.

Hoffman CS and Winston F (1989). A transcriptionally regulated expression vector for the fission yeast Schizosaccharomyces pombe. Gene 84: 473-479.

Hoffman CS and Winston F (1990). Isolation and characterization of mutants constitutive for expression of the fbp1 gene of Schizosaccharomyces pombe. Genetics 124: 807-816.

Hoffman CS and Winston F (1991). Glucose repression of transcription of the Schizosaccharomyces pombe fbp 1 gene occurs by a cAMP signaling pathway. Genes Dev. 5: 561-571.

Ikner A and Shiozaki K (2005). Yeast signaling pathways in the oxidative stress response. Mutat. Res. 569: 13-27.

Johnston M (1999). Feasting, fasting and fermenting. Glucose sensing in yeast and other cells. Trends Genet. 15: 29-33.

Kanoh J, Watanabe Y, Ohsugi M, Iino Y, et al. (1996). Schizosaccharomyces pombe gad7+ encodes a phosphoprotein with a bZIP domain, which is required for proper G1 arrest and gene expression under nitrogen starvation. Genes Cells 1: 391-408.

Kig C, Turkel S and Temizkan G (2005). Isolation and characterization of glucose derepressed invertase mutants from Schizosaccharomyces pombe. Biosci. Biotechnol. Biochem. 69: 2475-2478.

Lin SJ, Kaeberlein M, Andalis AA, Sturtz LA, et al. (2002). Calorie restriction extends Saccharomyces cerevisiae lifespan by increasing respiration. Nature 418: 344-348.

Madrid M, Soto T, Franco A, Paredes V, et al. (2004). A cooperative role for Atf1 and Pap1 in the detoxification of the oxidative stress induced by glucose deprivation in Schizosaccharomyces pombe. J. Biol. Chem. 279: 41594-41602.

Maeda T, Mochizuki N and Yamamoto M (1990). Adenylyl cyclase is dispensable for vegetative cell growth in the fission yeast Schizosaccharomyces pombe. Proc. Natl. Acad. Sci. U. S. A. 87: 7814-7818.

Maeda T, Wurgler-Murphy SM and Saito H (1994). A two-component system that regulates an osmosensing MAP kinase cascade in yeast. Nature 369: 242-245.

Matsuzawa T, Fujita Y, Tohda H and Takegawa K (2012). Snf1-like protein kinase Ssp2 regulates glucose derepression in Schizosaccharomyces pombe. Eukaryotic Cell 11: 159-167.

Neely LA and Hoffman CS (2000). Protein kinase A and mitogen-activated protein kinase pathways antagonistically regulate fission yeast fbp1 transcription by employing different modes of action at two upstream activation sites. Mol. Cell. Biol. 20: 6426-6434.

Palabiyik B, Kig C, Pekmez M, Dalyan L, et al. (2012). Investigation of the relationship between oxidative stress and glucose signaling in Schizosaccharomyces pombe. Biochem. Genet. 50: 336-349.

Petit T, Blazquez MA and Gancedo C (1996). Schizosaccharomyces pombe possesses an unusual and a conventional hexokinase: biochemical and molecular characterization of both hexokinases. FEBS Lett. 378: 185-189.

Pfaffl MW (2001). A new mathematical model for relative quantification in real-time RT-PCR. Nucleic Acids Res. 29 : e45.

Pick E and Keisari Y (1980). A simple colorimetric method for the measurement of hydrogen peroxide produced by cells in culture. J. Immunol. Methods 38: 161-170.

Quinn J, Findlay VJ, Dawson K, Millar JB, et al. (2002). Distinct regulatory proteins control the graded transcriptional response to increasing $\mathrm{H}(2) \mathrm{O}(2)$ levels in fission yeast Schizosaccharomyces pombe. Mol. Biol. Cell 13: 805-816.

Ribeiro MJ, Reinders A, Boller T, Wiemken A, et al. (1997). Trehalose synthesis is important for the acquisition of thermotolerance in Schizosaccharomyces pombe. Mol. Microbiol. 25: 571-581.

Rincon AM, Codon AC, Castrejon F and Benitez T (2001). Improved properties of baker's yeast mutants resistant to 2-deoxy-D-glucose. Appl. Environ. Microbiol. 67: 4279-4285.

Rolland F, Winderickx J and Thevelein JM (2002). Glucose-sensing and -signalling mechanisms in yeast. FEMS Yeast Res. 2: 183-201. 
Roux AE, Leroux A, Alaamery MA, Hoffman CS, et al. (2009). Pro-aging effects of glucose signaling through a G protein-coupled glucose receptor in fission yeast. PLoS Genet. 5: e1000408.

Roux AE, Arseneault G, Chartrand P, Ferbeyre G, et al. (2010). A screen for genes involved in respiration control and longevity in Schizosaccharomyces pombe. Ann. N. Y. Acad. Sci. 1197: 19-27.

Samejima I, Mackie S and Fantes PA (1997). Multiple modes of activation of the stress-responsive MAP kinase pathway in fission yeast. EMBO J. 16: 6162-6170.

Shiozaki K and Russell P (1996). Conjugation, meiosis, and the osmotic stress response are regulated by Spc1 kinase through Atf1 transcription factor in fission yeast. Genes Dev. 10: 2276-2288.

Shiozaki K, Shiozaki M and Russell P (1997). Mcs4 mitotic catastrophe suppressor regulates the fission yeast cell cycle through the Wik1-Wis1-Spc1 kinase cascade. Mol. Biol. Cell 8: 409-419.

Stettler S, Warbrick E, Prochnik S, Mackie S, et al. (1996). The wis1 signal transduction pathway is required for expression of cAMP-repressed genes in fission yeast. J. Cell Sci. 109 (Pt 7): 1927-1935.

Suslu KG, Palabiyik B and Temizkan G (2011). The studies on the relationship between glucose repression and oxidative stres response in the fission yeast Schizosaccharomyces pombe. Genet. Mol. Res. 10: 4041-4047.

Welton RM and Hoffman CS (2000). Glucose monitoring in fission yeast via the gpa2 Ga, the git5 Gß and the git3 putative glucose receptor. Genetics 156: 513-521.

Wilkinson MG, Samuels M, Takeda T, Toone WM, et al. (1996). The Atf1 transcription factor is a target for the Sty1 stress-activated MAP kinase pathway in fission yeast. Genes Dev. 10: 2289-2301.

Zuin A, Carmona M, Morales-Ivorra I, Gabrielli N, et al. (2010). Lifespan extension by calorie restriction relies on the Sty1 MAP kinase stress pathway. EMBO J. 29: 981-991. 